$\left(\begin{array}{l}\text { Jpn. J. Hosp. Pharm. } \\ \text { 26(1) } 102-109(2000)\end{array}\right)$

\title{
Studies on Hospital Pharmaceutical Manufacturing (V) Preparation and Preliminary Clinical Evaluation of Serotonin Creatinin Sulfate Injection
}

\author{
MOEMI SAITO $* \dagger^{1}$, MASAHIRO HOSHI $\dagger^{1}$, HIROSHI OGATA $\dagger^{1}$, TAKEHIKO MIKAWA $\dagger^{1}$, \\ HIROHIDE YOSHIDA $\dagger^{1}$, KAZUHIKO KUROSAWA $\dagger^{2}$, AKIRA HIROSAKA $\dagger^{2}$, \\ YUKIO MARUYAMA $\dagger^{2}$ and KIYOTO EDO $\dagger^{1}$ \\ Pharmacy, Fukushima Medical University Hospital $\dagger^{1}$
}

The First Department of Internal Medicine, Fukushima Medical University $\dagger^{2}$

\author{
$\left(\begin{array}{l}\text { Received June 1, } 1999 \\ \text { Accepted November 1, } 1999\end{array}\right)$
}

\begin{abstract}
Serotonin creatinine sulfate (5-HTCS) injection, one of our hospital pharmaceutical manufactured products, is used as a diagnostic reagent for small coronary resistance vessels. 5-HTCS injection was prepared in a clean room under sterile conditions. All lots of the 5-HTCS injections were checked for any foreign matter and particles, sterility, the presence of pyrogens and the content of 5-HTCS. The stability of 5-HTCS injections was investigated under various storage conditions. The remaining amount of 5-HTCS in the infusion solution was determined by spectrophotometry. The contents of 5-HTCS were unchanged for 6 months at $-20^{\circ} \mathrm{C}$ while kept in darkness and wrapped in foil. Under other storage conditions, at $5^{\circ} \mathrm{C}$ in darkness, at room temperature $\left(25 \pm 0.5^{\circ} \mathrm{C}\right)$ in darkness wrapped in foil, at room temperature $\left(25 \pm 0.5^{\circ} \mathrm{C}\right)$ under intense light (1000 Lux fluorescent light) and at $40^{\circ} \mathrm{C}$ in darkness wrapped in foil, a considerable rise of the peak at $275 \mathrm{~nm}$ was observed. These results shows that the degradation of 5-HTCS in infusion solutions is temperature dependent and 5-HTCS injections should thus be stored frozen and foil wrapped at $-20^{\circ} \mathrm{C}$ until the day of the use. Furthermore, the effect of 5-HTCS on small coronary resistance vessels differed from acetylcholine which had been already been used as a daily diagnostic tool. This suggests that a 5-HTCS injection may be an effective diagnostic tool for evaluating the small coronary resistance vessels' functional level that can not be evaluated by coronary angiography.
\end{abstract}

Key words — serotonin creatinine sulfate injection, hospital pharmaceutical manufacturing, preparation, stability, preliminary clinical evaluation

\section{Introduction}

Serotonin is found in many cells, such as neurons, platelets, mast cells and enterochromaffin cells, however the highest amount is stored in platelets. Serotonin is released from aggregating platelets, to which the endothelium is continuously exposed, and seems to play an important role in

$\dagger^{1,2}$ 福島市光が丘 1 番地 ; 1, Hikarigaoka, Fukushima-shi, 960-1295 Japan

* $\quad$ Studies on Hospital Pharmaceutical Manufacturing (IV), Jpn. Soc. Hosp. Pharm., 34, 1029-1032 (1998). 
the occurrence of coronary atherosclerosis by facilitating platelet aggregation ${ }^{1)}$.

It is considered that serotonin has divergent effects on coronary artery dimensions and blood flow, in that, it shows vasodilating effects on normal human coronary arteries, but it shows vasoconstricting effects when the endothelium is damaged, as in coronary artery disease ${ }^{2.3)}$.

The precise effect of serotonin on coronary circulation is not yet clearly understood, particularly on coronary microcirculation in various heart diseases. The clinical study protocol using serotonin injection was planned by cardiologists of the First Department of Internal Medicine, for evaluation of the microvascular response to some vasoactive agents. Because the serotonin injection is not commercially available in Japan, we prepared the serotonin creatinine sulfate (5-HTCS) injection as a hospital pharmaceutical product.

The purpose of this study was to prepare the 5-HTCS injection and to examine its stability in infusion solutions under the expected storage conditions in clinical use. A preliminary clinical study of the preparation was also performed.

\section{Materials and Methods}

\section{Materials}

Commercial 5-HTCS (Lot SKG 1167) was purchased from Wako Pure Chemical Industries, Ltd. (Osaka, Japan). Standard 5-HTCS was obtained according to the literature ${ }^{4,5}$. Briefly, 5-HTCS was obtained by recrystallization from acetone and water. Recrystallized 5-HTCS was dried at $80^{\circ} \mathrm{C}$ over phosphorus pentoxide in vacuo to a constant weight. No degradation product of 5-HTCS was found with HPLC. 5\% glucose solution for injection was purchased from Otuka Medical Products Co., Ltd. (Tokyo, Japan). All other chemicals and solvents used were of analytical or reagent grade.

\section{Preparation of 5-HTCS injection}

5-HTCS injection was prepared following the method of Golino et al . ${ }^{3)}$ The content of 5-HTCS injection that was approved in an institutional review board for hospital pharmaceutical manufacturing was 5-HTCS $100 \mu \mathrm{g} / 5 \%$ glucose $1 \mathrm{~mL} /$ ampule. 5-HTCS injection was prepared under sterile conditions. In the dark, $10.0 \mathrm{mg}$ of standard 5-HTCS was completely dissolved in an adequate volume of $5 \%$ glucose for injection. Then, 5-HTCS solution was adjusted to $100 \mathrm{~mL}$ in $5 \%$ glucose solution for injection. This solution was filtered through a membrane filter (Sterivex-GV $0.22 \mu \mathrm{m}$, Millipore Co., Tokyo, Japan). This solution $(1.5 \mathrm{~mL})$ was put in a light resistant 5 $\mathrm{mL}$ ampule (Racoon Steri Ample, Mitarika Co., Ltd., Osaka Japan). The air in ampules was displaced by nitrogen, and then the ampules were sealed. The content of 5-HTCS in the injection should be $100 \mu \mathrm{g} / \mathrm{mL}$ (Chart 1 ). The ampules of all lots were checked for foreign matter and particles visually according to the U. S. Pharmacopeia 23 National Formulary 18 .

Chart 1. Method of Preparation of 5-HTCS Injection

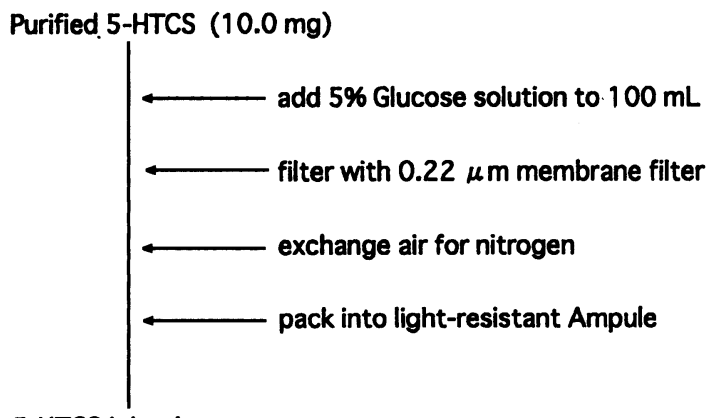

5-HTCS Injection 


\section{Monitoring of 5-HTCS stability in 5-HTCS injection}

Monitoring of 5-HTCS stability in the injection was done with a double-beam spectrophotometer (Hitachi 557, Hitachi, Ltd., Tokyo, Japan). The optical density of the solution was measured at $\lambda$ $\max 275 \mathrm{~nm}$. Two samples were measured from each lot. Each sample was diluted 2-fold with water to an accurately measured injection volume at a concentration of $50 \mu \mathrm{g} / \mathrm{mL}$. Spectrophotometry system was calibrated with standard solutions of 5-HTCS in the range of 10.0 to $90.0 \mu \mathrm{g} /$ $\mathrm{mL}$ in water. Content of 5-HTCS in the injection was determined using the calibration curve prepared by standard 5-HTCS solutions. The standard curve was linear $(r=0.998)$ over the drug concentration range of 10.0 to $90.0 \mu \mathrm{g} / \mathrm{mL}$.

\section{Assay of 5-HTCS}

The analysis of 5-HTCS with HPLC was modified from the method of Kele et al. ${ }^{6}$ Quantitative detection of HPLC was performed by Hitachi L-6200 system. An Inertsil ODS-2 (4.6×250 mm) column was used with the mobile phase at a constant flow rate of $0.6 \mathrm{~mL} / \mathrm{min}$ at $25 \pm 0.5^{\circ} \mathrm{C}$. The injection volume was $20 \mu \mathrm{L}$. The elution pattern was recorded by a UV detector set at a wavelength of $275 \mathrm{~nm}$. The mobile phase was a mixture of $\mathrm{CH}_{3} \mathrm{CN}: \mathrm{H}_{2} \mathrm{O}: \mathrm{CF}_{3} \mathrm{COOH}=400: 1600: 1$. The mobile phase was freshly prepared before each day of sample analysis. The typical retention time for 5-HTCS was $5.85 \mathrm{~min}$. Each sample was assayed in duplicate by HPLC.

\section{The Sterility Test and the Endotoxin Test}

5-HTCS injection was tested using the Sterility test according to the Japanese Pharmacopeia (JP) XIII. Media for the tests were Fluid Thioglycollate Medium I and Soybean Casein Digest Medium. 5-HTCS injection was added to each of the two media. The test mixture was incubated for 14 days with Fluid Thioglycollate Medium I at $35^{\circ} \mathrm{C}$, and with Soybean Casein Digest Medium at $25^{\circ} \mathrm{C}$. Because microbial contamination was not demonstrate by the procedure given in the JP XIII, we considered that 5-HTCS injection met the requirements of the test.

The content of endotoxin in 5-HTCS injection was measured using the Endotoxin test according to the JP XIII. Limulus HS-J Single Test Wako (lot DMF 1388) was used for this test. Any containers or utensils employed were treated so as to destroy any surface endotoxins that may be present, such as heating in an oven at $250^{\circ} \mathrm{C}$ for 1.5 hours.

\section{The Stress Conditions}

5-HTCS injection was examined under the expected storage conditions in clinical use. Namely,5HTCS injection was stored under the following conditions for 6 months. : (1) at $-20^{\circ} \mathrm{C}$ in the dark wrapped in foil, (2) at $5^{\circ} \mathrm{C}$ in the dark wrapped in foil, (3) at room temperature $\left(25 \pm 0.5^{\circ} \mathrm{C}\right)$ in the dark wrapped in foil, (4) at room temperature $\left(25 \pm 0.5^{\circ} \mathrm{C}\right)$ under intense light (1000 Lux fluorescent light), (5) at $40^{\circ} \mathrm{C}$ in the dark wrapped in foil. Exposure to these conditions resulted in remaining percentages of 5-HTCS, all of which were measured by Spectrophotometry. Visual inspection for color change and precipitate formation was performed for each sample with the naked eye under 1000 Lux fluorescent light.

Content of 5-HTCS in the injection was determined using the calibration curve prepared by standard 5-HTCS solutions with a double-beam spectrophotometer.

\section{Clinical Examination}

The clinical study protocol was designed to analyze a coronary flow velocity (average peak velocity : APV) change before and after intracoronary administration of acetylcholine $(\mathrm{ACH}): 50 \mu \mathrm{g} /$ 
$5 \mathrm{~mL} / 30 \mathrm{sec}$, and two kinds of concentrations of 5 -HTCS : $10 \mu \mathrm{g} / 10 \mathrm{~mL} / 60 \mathrm{sec}, 100 \mu \mathrm{g} / 10 \mathrm{~mL} / 60$ sec. The flow velocity was continuously measured using guidewire with a $12 \mathrm{MHz}$ transducer at its distal tip (FloWire : Cardiometrics; Mountain View, CA) which was placed in a proximal part of the left anterior descending artery.

The clinical study was performed on 3 patients who received cardiac catheterization for the diagnosis of angina pectoris (AP), vasospastic angina (VSA) and aortic regurgitation (AR), respectively. Patients with unstable angina, acute myocardial infarction and advanced coronary heart disease, such as three vessel disease, were excluded.

The study was approved by the institutional review board of Fukushima Medical University Hospital, and written informed consent was obtained from all patients.

\section{Results}

\section{Preparation and quantitative determination of 5-HTCS in the injection}

Preparation of 5-HTCS injection is described in detail in "Materials and Methods". All nine lots of 5-HTCS injections were prepared between March 1997 and June 1998. No foreign matter and particles in any lots were observed (data not shown). Furthermore, the mean percentages of the initial 5-HTCS concentration remaining, which were measured using double-beam spectrophotometer, were $99.8-100.6 \%$ for all the concentrations tested. Thus, all lots met the required $95.0-105.0 \%$ by quantitative determination during this period (date not shown).

\section{The Sterility Test and the Endotoxin Test of 5-HTCS injection}

The Sterility test and the Endotoxin test were performed as quality control tests for contamination by microorganisms.

The Sterility tests on 9 lots of 5-HTCS injections prepared between March 1997 and June 1998 showed that no growth was observed during the 14 days in Fluid Thioglycollate Medium I and Soybean Casein Digest Medium (data not shown).

Before the Endotoxin test was examined, the test for inhibition or enhancement was performed . This result was valid for 5-HTCS injection. The geometric endpoint concentration of 5-HTCS injection under test was not more than $0.03 \mathrm{EU} / \mathrm{mL}$ (Table 1 ).

\section{Stability of 5-HTCS injection}

To determine the storage period and the storage condition of 5-HTCS injection, the stability of 5HTCS injection under various conditions was studied.

When 5-HTCS injection was stored at $-20^{\circ} \mathrm{C}$ in the dark wrapped in foil for up to 6 months, the content of 5-HTCS in the injection did not change as compared with the initial content and there was no visual evidence of precipitation or color change in any of the samples. However, the optical density at $275 \mathrm{~nm}$ increased markedly when stored at $40^{\circ} \mathrm{C}$ in the dark wrapped in foil after 6 months of storage, and the contents of 5-HTCS increased slightly when stored under the other three conditions (Fig 1 ). Therefore, the concentration of 5-HTCS at $-20^{\circ} \mathrm{C}$ in the dark wrapped in foil was used as a control level. Fig 2 shows UV spectrum of 5-HTCS after 3 months of storage. Compared with a control line at $-20^{\circ} \mathrm{C}$ in the dark wrapped in foil, a considerable rise of the peaks at $275 \mathrm{~nm}$ and $372 \mathrm{~nm}$ were observed at $40^{\circ} \mathrm{C}$ in the dark wrapped in foil. Slight rise of the peaks at these two points was also observed at $5^{\circ} \mathrm{C}$ in the dark wrapped in foil, at room temperature $\left(25 \pm 0.5^{\circ} \mathrm{C}\right)$ under intense light $(1000$ Lux fluorescent light $)$ and at room temperature $(25 \pm 0.5$ 
Table 1. The Endotoxin Test of 5-HTCS Injection

\begin{tabular}{|c|c|c|c|c|c|c|c|c|}
\hline \multirow[t]{2}{*}{ Lot No } & \multirow{2}{*}{$\begin{array}{l}\text { The number of } \\
\text { measurement }\end{array}$} & \multirow{2}{*}{$\begin{array}{l}\text { Water for } \\
\text { Injection }\end{array}$} & \multicolumn{4}{|c|}{$\mathrm{CSE}^{*}(\mathrm{EU} / \mathrm{mL})$} & \multirow{2}{*}{$\begin{array}{l}5-\mathrm{HTCS} \\
\text { Injection }\end{array}$} & \multirow{2}{*}{\begin{tabular}{|l}
5 -HTCS Injection \\
+ CSE $0.0625 \mathrm{EU} / \mathrm{mL}$
\end{tabular}} \\
\hline & & & 0.0078 & 0.0156 & 0.0313 & 0.0625 & & \\
\hline \multirow{2}{*}{19970312} & 1 & - & - & - & + & $t$ & - & + \\
\hline & 2 & - & - & - & + & + & - & + \\
\hline \multirow[t]{2}{*}{19970411} & 1 & - & - & - & + & + & - & + \\
\hline & 2 & - & - & - & + & + & - & + \\
\hline \multirow[t]{2}{*}{19970526} & 1 & - & - & - & + & + & - & + \\
\hline & 2 & - & - & - & + & + & - & + \\
\hline \multirow[t]{2}{*}{19970729} & 1 & - & - & - & + & + & - & + \\
\hline & 2 & - & - & - & + & + & - & + \\
\hline \multirow[t]{2}{*}{19970802} & 1 & - & - & - & + & + & - & + \\
\hline & 2 & - & - & - & + & + & - & + \\
\hline \multirow[t]{2}{*}{19971001} & 1 & - & - & + & + & + & - & + \\
\hline & 2 & - & - & + & + & + & - & + \\
\hline \multirow[t]{2}{*}{19971208} & 1 & - & - & - & + & + & - & + \\
\hline & 2 & - & - & - & + & + & - & + \\
\hline \multirow[t]{2}{*}{19980209} & 1 & - & - & - & + & + & - & + \\
\hline & 2 & - & - & - & + & + & - & + \\
\hline \multirow[t]{2}{*}{19980610} & 1 & - & - & - & + & + & - & + \\
\hline & 2 & - & - & - & + & + & - & + \\
\hline
\end{tabular}

5-HTCS injection was measured using the Endotoxin test according to Japanese Pharmacopela $\mathbf{X}$.

* Control Standard Endotoxin + : positive - : negative

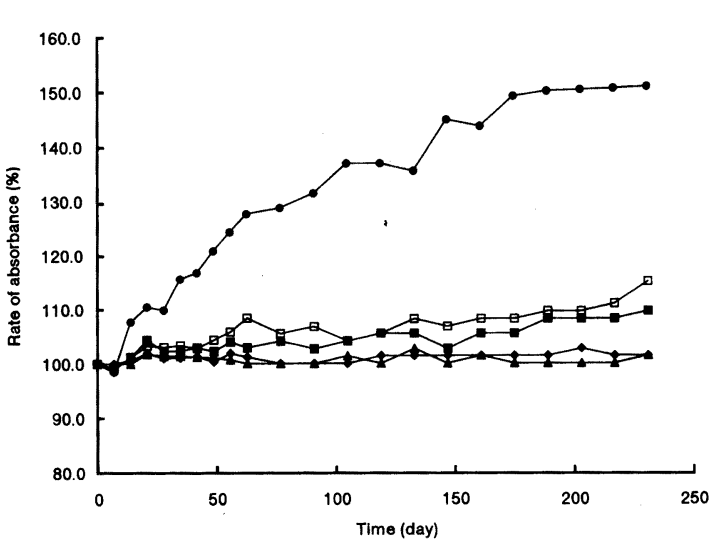

Fig. 1. Stability of 5-HTCS Injection $-20^{\circ} \mathrm{C}$ in the dark wrapped in foil ( - ), $5^{\circ} \mathrm{C}$ in the dark wrapped in foil (-), 25 $\pm 0.5^{\circ} \mathrm{C}$ in the dark wrapped in foil (- - , $25 \pm 0.5^{\circ} \mathrm{C}$ under 1000 Lux fluorescent light $(\square), 40^{\circ} \mathrm{C}$ in the dark wrapped in foil (-).

Values expressed as the average of two experiments. The time course of the residual concentration against the initial concentration was determined as described in Materials and Methods.

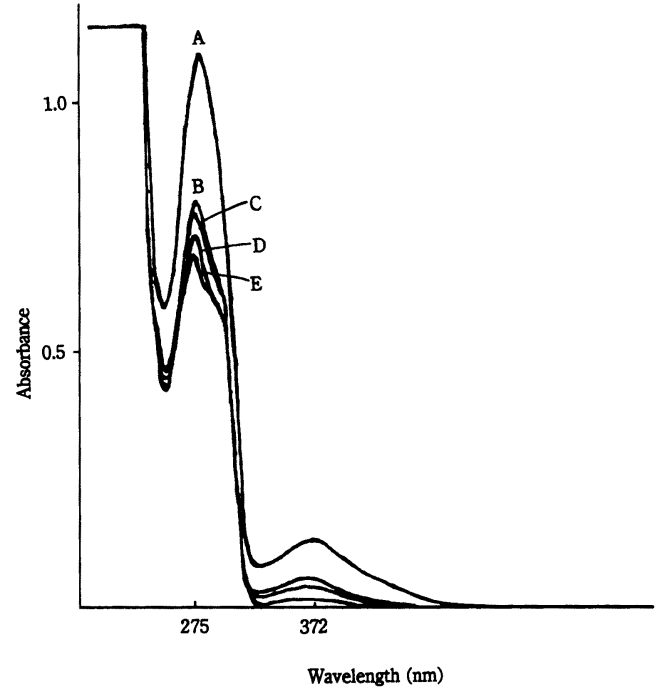

Fig. 2. UV Spectrum of 5-HTCS Injection Under Various Conditions

The assay was performed as described in Materials and Methods.

A : $40^{\circ} \mathrm{C}$ in the dark wrapped in foil, B : 25 $\pm 0.5^{\circ} \mathrm{C}$ under 1000 Lux fluorescent light, $\mathrm{C}: 25 \pm 0.5^{\circ} \mathrm{C}$ in the dark wrapped in foil, $\mathrm{D}: 5^{\circ} \mathrm{C}$ in the dark wrapped in foil, $\mathrm{E}$ : $-20^{\circ} \mathrm{C}$ in the dark wrapped in foil 
${ }^{\circ} \mathrm{C}$ ) in the dark wrapped in foil. Remarkable change in color was observed at $40^{\circ} \mathrm{C}$ in the dark wrapped in foil, but slight changes in color was observed under other three conditions. No precipitate formation was observed for any conditions.

Because of the rise of the peak at $275 \mathrm{~nm}$, degradation products were studied by HPLC. Fig 3 shows HPLC chromatograms of 5-HTCS injections. The peak area of retention time at 5.85 minutes at $40^{\circ} \mathrm{C}$ in the dark wrapped in foil was lower than that at $-20^{\circ} \mathrm{C}$ in the dark wrapped in foil, while the peak area at 6.70 minutes at $40^{\circ} \mathrm{C}$ in the dark wrapped in foil was higher.

\section{Case Studies}

Patient characteristics and ratio of Base-APV and Peak-APV after administration of each drug are shown in the Table 2 . In all the 3 patient the ratio after administration of $\mathrm{ACH}$ was different from that of 5-HTCS $10 \mu \mathrm{g}$ and 5-HTCS $100 \mu \mathrm{g}$. Subjective symptoms resulting from administration of 5-HTCS included transient chest pain, chest oppression, palpitation and chest discomfort. Objective symptoms included electrocardiographic ST changes, slightly increased heart rate, and coronary artery spasms.

\section{Discussion}

We prepared 5-HTCS injection and investigated its stability and its shelf life. The preparation of 5-HTCS injection was performed under sterile conditions. It was rigorously checked for sterility, the presence of endotoxins and the content of 5-HTCS for each lot.

Content of 5-HTCS in infusion solution remained at $95.0-105.0 \%$ of its initial content after 6 months. No microorganismgrowth was observed after 6 months by the Sterility test. This suggests that 5-HTCS injection meets the requirements of the test for Sterility.

The geometric endpoint concentration of 5-HTCS injection by Endotoxin test was not more than $0.03 \mathrm{EU} / \mathrm{mL}$. 5-HTCS injection met the requirements of the Endotoxin test. Therefore, 5-HTCS injection was stable for up to 6 months at $-20^{\circ} \mathrm{C}$ in the dark wrapped in foil. The safety of 5-HTCS injection for up to 6 months was confirmed by these examinations.

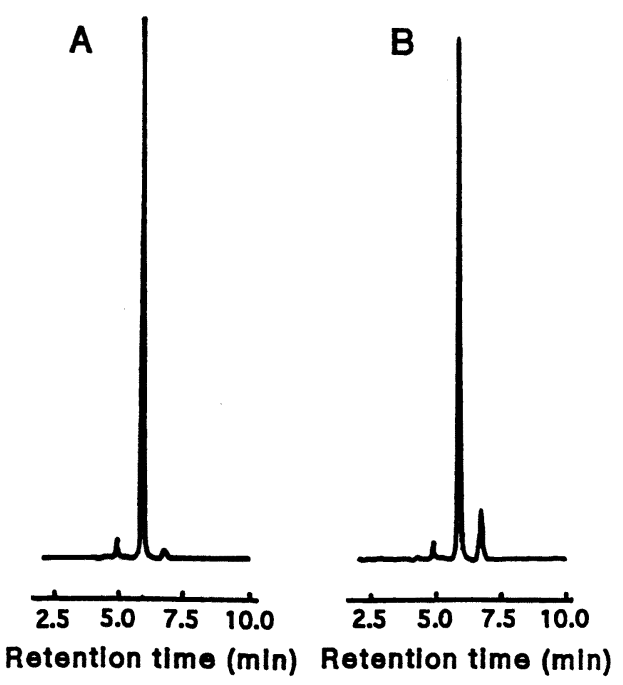

Fig. 3. HPLC Profiles of 5-HTCS Injection

A) Storage : $-20^{\circ} \mathrm{C}$ in the dark wrapped in foil,

B) Storage : $40^{\circ} \mathrm{C}$ in the dark wrapped in foil.

[condition] Apparatus : Hitachi L-6200, Column : Inertsil ODS $(4.6 \times 250 \mathrm{~mm})$, Detection: UV $275 \mathrm{~nm}$, Detector sensitivity : 0.1 AUFS, Mobile phase: $\mathrm{CH}_{3} \mathrm{CN}: \mathrm{H}_{2} \mathrm{O}$ : $\mathrm{CF}_{3} \mathrm{COOH}=400: 1600: 1$, Flow rate $: 0.6$ $\mathrm{mL} / \mathrm{min}$. The assay was performed as described in Materials and Methods. 
Table 2. Patient Characteristics and Ratio of Bese-APV and Peak-APV after Drug Administration

\begin{tabular}{ccccccc}
\hline $\begin{array}{c}\text { Patient } \\
\text { No }\end{array}$ & $\begin{array}{c}\text { Age } \\
\text { (years) }\end{array}$ & Sex & Disease & $\begin{array}{c}\text { Acetylcholine } \\
50 \mu \mathrm{g}\end{array}$ & $\begin{array}{c}5-\mathrm{HTCS} \\
10 \mu \mathrm{g}\end{array}$ & $\begin{array}{c}5-\mathrm{HTCS} \\
100 \mu \mathrm{g}\end{array}$ \\
\cline { 5 - 7 } & & & \multicolumn{3}{c}{ PAPV $^{1)} / \mathrm{BAPV}^{2)}$} \\
\hline 1 & 49 & $\mathrm{M}$ & $\mathrm{AP}^{3)}$ & 2.9 & 1.1 & 1.1 \\
2 & 40 & $\mathrm{M}$ & $\mathrm{VSA}^{4)}$ & 4.3 & 1.8 & 1.0 \\
3 & 48 & $\mathrm{M}$ & $\mathrm{AR}^{5)}$ & 4.4 & 1.4 & 1.2 \\
\hline
\end{tabular}

1) Peak-APV (Peak- Average peak velocity) : Average peak velocity after drug administration , 2) Base-APV (Base-Average peak velocity) : Average peak velocity before drug administration, 3) Angina pectoris, 4) vasospastic angina, 5) aortic regurgitation

Next, we evaluated the stability of this injection under the various conditions for up to 6 months. When 5-HTCS injection was stored at $-20^{\circ} \mathrm{C}$ in the dark wrapped in foil, no change in the concentration and color was observed after 6 months of storage. However, when was stored at $40^{\circ} \mathrm{C}$ in the dark wrapped in foil, a marked increase of the peaks at $275 \mathrm{~nm}$ and change in color into yellow were observed even after 3 months of storage. Furthermore, a peak area at $372 \mathrm{~nm}$ which was not detected at $-20^{\circ} \mathrm{C}$ in the dark wrapped in foil was observed. Under all conditions, the peaks at $275 \mathrm{~nm}$ and $372 \mathrm{~nm}$ increased in the order of : at $40^{\circ} \mathrm{C}$ in the dark wrapped in foil $>$ at room temperature $\left(25 \pm 0.5^{\circ} \mathrm{C}\right)$ under intense light $(1000$ Lux fluorescent light $)>$ at room temperature $(25 \pm$ $0.5^{\circ} \mathrm{C}$ ) in the dark wrapped in foil as compared with the control level (at $-20^{\circ} \mathrm{C}$ in the dark wrapped in foil). These findings indicate that the stability of 5-HTCS in infusion solution is affected by temperature. 5-HTCS injection was most stable at $-20^{\circ} \mathrm{C}$ in the dark wrapped in foil during 6 months, but under the other conditions this injection started to decompose even after 3 months of storage.

Furthermore, peak 1 (retention time 4.90), peak 2 (retention time 5.85) and peak 3 (retention time 6.70) was fractionated by HPLC. Each fraction was measured by double-beam spectrophptometer. The absorbances of fraction 1, 2 and 3 were observed at both $275 \mathrm{~nm}$ and $372 \mathrm{~nm}$, at $275 \mathrm{~nm}$ and at $275 \mathrm{~nm}$, respectively. It seemed that degradation products contributed to the rise of absorbance at $275 \mathrm{~nm}$. However, no degradation product was identified. It is a subject of furture study to examine a mechanism of decomposition. Therefore, we conclude that 5-HTCS injection is able to store at $-20^{\circ} \mathrm{C}$ in the dark wrapped in foil during 6 months. Because 5-HTCS injection is affected by temperature, sufficient attention should be paid to the storage of this injection and the residual solution should not be used if the 5-HTCS injection is thawed.

5-HTCS injection was used in the protocol for additional drug testing to evaluate its effect on the small coronary resistance vessels. Both 5-HTCS and ACH have a vasodilating effect on normal human coronary arteries. Conversely, 5-HTCS and ACH constrict coronary arteries if the endothelium is damaged. Therefore, it is probable that the effect of these two drugs on the small coronary resistance vessels occurs via the same pathway. However, in all three patients, PAPV/BAPV (ratio) was different between $10 \mu \mathrm{g}$ and $100 \mu \mathrm{g}$ of 5-HTCS and $50 \mu \mathrm{g}$ of ACH. Because PAPV/BAPV shows the rate of velocity of left anterior descending coronary artery, the rise of PAPV/BAPV 
suggests that small coronary vessels' resistance can be reduced. This study demonstrates that the effect of 5-HTCS on small coronary resistance vessels is similar to or stronger than ACH. This finding suggests that 5-HTCS injection may have a diagnostic use in evaluating the small coronary resistance vessels' functional level that can not be evaluated by coronary angiography.

Further study in search of clinical applications is underway.

\section{Acknowledgement}

This work was supported in part by a Grant-in-Aid for Scientific Research (No. 09922026) from the Ministry of Education, Science and Culture of Japan. The authors are grateful to Dr. Machiko Watanabe for her advice.

\section{References}

1) P. M. Vanhoutte and R. A. Cohen, Biochem. Pharm., 32, 3671-3674 (1983).

2) T. M. Cocks and J. A. Angus, Nature, 305, 627-630 (1983).

3) P. Golino, F. Piscione, J. T. Willerson, M. C. Bigazzi, A. Focaccio, B. Villari, C. Indolfi, E. Russolillo and M. Condorelli, N. Engl. J. Med., 324, 641-648 (1991).

4) M. M. Rapport, A. A. Green and I. H. Page, J. Biol. Chem., 176, 1243-1251 (1948).

5) M. M. Rapport, J. Biol. Chem., 180, 961-969 (1949).

6) M. Kele and R. Ohmacht, J. Chrom. A, 730, 59-62 (1996). 